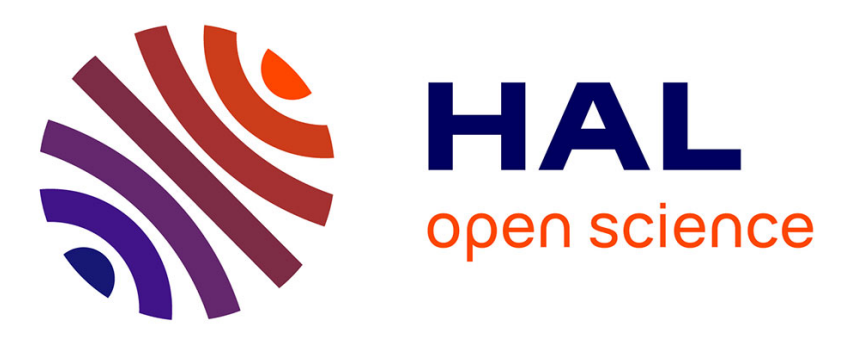

\title{
A 40-year-old divided highway does not prevent gene flow in the alpine newt Ichthyosaura alpestris
}

Jérôme Prunier, Bernard Kaufmann, Jean-Paul Léna, Serge Fenet, Francois Pompanon, Pierre Joly

\section{- To cite this version:}

Jérôme Prunier, Bernard Kaufmann, Jean-Paul Léna, Serge Fenet, Francois Pompanon, et al.. A 40-year-old divided highway does not prevent gene flow in the alpine newt Ichthyosaura alpestris. Conservation Genetics, 2014, 15 (2), pp.453-468. 10.1007/s10592-013-0553-0 . halsde-00968131v2

\section{HAL Id: halsde-00968131 https://hal.science/halsde-00968131v2}

Submitted on 11 Dec 2015

HAL is a multi-disciplinary open access archive for the deposit and dissemination of scientific research documents, whether they are published or not. The documents may come from teaching and research institutions in France or abroad, or from public or private research centers.
L'archive ouverte pluridisciplinaire HAL, est destinée au dépôt et à la diffusion de documents scientifiques de niveau recherche, publiés ou non, émanant des établissements d'enseignement et de recherche français ou étrangers, des laboratoires publics ou privés.

$$
\text { Copyright }
$$


1 Jérôme G. Prunier ${ }^{\mathrm{a}, \mathrm{b}}$, Bernard Kaufmann ${ }^{\mathrm{b}}$, Jean-Paul Léna ${ }^{\mathrm{b}}$, Serge Fenet ${ }^{\mathrm{c}}$, François Pompanon ${ }^{\mathrm{d}}$ and

2 Pierre Joly ${ }^{b}$

3

4 A forty-year-old divided highway does not prevent gene flow

\section{5 in the alpine newt Ichthyosaura alpestris.}

6

$7 \quad{ }^{a}$ Ecosphère, 3bis rue des Remises, 94100 Saint Maur des Fossés, France

$8{ }^{b}$ Université de Lyon; UMR5023 Ecologie des Hydrosystèmes Naturels et Anthropisés; Université Lyon

9 1; ENTPE; CNRS; Villeurbanne, F-69622, France.

$10{ }^{c}$ Université de Lyon, UMR 5205 Laboratoire d'Informatique en Image et Systèmes d'information, Bat.

11 Nautibus, Université Lyon 1; CNRS; Villeurbanne, F-69622, France.

$12{ }^{d}$ Université Joseph Fourier, Laboratoire d'Ecologie Alpine, CNRS, UMR 5553, 2233 Rue de la Piscine,

1338041 Grenoble Cedex 9, France.

14

15 Corresponding author:

16 Jérôme G. Prunier

17 Current address : Université Catholique de Louvain, 4-5 Croix du Sud, bte L7.07.14, Institute of Life

18 Sciences (ISV), Louvain-la-Neuve, B-1348, Belgium

19 Fax: $(+32) 10473872$

20 Email: jerome.prunier@gmail.com

21

22 


\section{Abstract}

24 Roads are of major concern in conservation biology, as they are known to restrict animal movements through landscape fragmentation, and may therefore impact genetic patterns in native terrestrial organisms. We assessed the effect of two large-scale transportation infrastructures, a 40 year-old highway and a 30 year-old high-speed railway, on the spatial genetic structure of the alpine newt Ichthyosaura alpestris, a highly nomadic amphibian. Genetic data were gathered following a targeted individual-based sampling scheme and analysed using both overlay and correlative methods. While simulations suggested that the highway may be old enough for a significant barrier effect to be detected, large-scale transportation infrastructures were never detected as barriers to gene flow: inferred genetic boundaries rather coincided with transition zones between major landscape entities. Furthermore, spatial principal component analysis, a method designed to reveal cryptic genetic spatial patterns in high gene flow species, counter-intuitively suggested that the highway may act as a potential dispersal corridor in lowquality habitats, thus challenging traditional hypotheses on road impacts in amphibians. Our study showed that considering local interactions between species, infrastructures and landscape-specific characteristics is essential for better understanding the potential impacts of roads on movement patterns in terrestrial organisms.

Keywords: amphibian, Bayesian clustering methods, correlative analyses, landscape genetics, highway, sPCA.

42 


\section{Introduction}

46 Roads constitute one of the most widespread forms of land use in contemporary landscapes and have been

47 the subject of numerous studies aiming to assess their impacts on natural populations (Trombulak and Frissell 2000; Balkenhol and Waits 2009). Roads are known to act as barrier to dispersal and gene flow (isolation-by-barrier, $I B B$ ), decreasing functional connectivity and increasing the genetic differentiation among individuals on each side of the infrastructure (Balkenhol and Waits 2009; Holderegger and Di Giulio 2010). The larger the size of a road (in terms of traffic volume and spatial dimensions), the higher the expected impact on both landscape configuration (Trombulak and Frissell 2000) and dispersal patterns (Holderegger and Di Giulio 2010). Large-scale transportation infrastructures (LTIs) such as highways and high-speed railways are thus of major concern in conservation biology. Barrier effects may be explained by mortality due to collisions, which obviously decreases gene exchanges across roads (Holderegger and Di Giulio 2010), but also by the modification of effective dispersal patterns (e.g. Riley et al. 2006). The presence of 'Jersey barriers' (Lesbarreres and Fahrig 2012) or fences for livestock exclusion (Dodd et al. 2004; Kuehn et al. 2007; Holderegger and Di Giulio 2010; Hepenstrick et al. 2012), as well as road avoidance due to physical or chemical alteration of the local environment may prevent animals from crossing LTIs and possibly lead them to increase their movement along road verges (Trombulak and Frissell 2000; McGregor et al. 2008; Balkenhol and Waits 2009). However, barrier effects are often alleviated by bridges, underpasses or specific road crossing structures, often coupled with guide fences (McGregor et al. 2008; Woltz et al. 2008) that can be used by dispersing animals. Small ground-dwelling animals such as amphibians are nevertheless suspected to be unable to encounter these crossing structures because of poor locomotive performances and specific orientation capabilities (Joly and Miaud 1993; Beebee 2013). As mortality due to collisions and road avoidance both depend on traffic volume and infrastructure width, divided highways might be considered stronger barriers to dispersal than high-speed railways. However, rails may also constitute a physical barrier for small ground-dwelling animals (Bartoszek and Greenwald 2009), because tracks are in close contact to the ballast, leaving no space for animals to move underneath, while the prominent head of tracks (when considering the cross sectional shape of rail) may prevent animals from climbing over them.

On a larger scale, modifications of the surrounding landscape configuration due to LTI could also impact wildlife dispersal patterns. For instance, LTIs are responsible for the alteration of surface-water 
habitats through flow re-routing and wetlands destruction (Trombulak and Frissell 2000), impacting both aquatic and semi-aquatic species. In the particular case of highways, road connections to urban areas improve rural-urban access and increase farmland value (Drescher et al. 2001). This often leads to the regrouping of cultivated farmlands, to the detriment of suitable landscape features such as wooded patches, extensively pastured meadows and aquatic or hedgerows networks. Conversely, LTIs may also contribute to the creation of large-scale, non-fragmented linear wetlands such as roadside ditches and grasslands corridors such as roadside verges, favoring movement of native but also exotic species in areas of low-quality or highly fragmented habitats (Tikka et al. 2001; Brisson et al. 2010; Holderegger and Di Giulio 2010). All these potential effects depend on complex interactions between species, infrastructures and landscape-specific characteristics, as well as the interactions with public policies and economic context (Woltz et al. 2008; Balkenhol and Waits 2009).

Direct and indirect effects of roads on wildlife have been described for years (Trombulak and Frissell 2000), leading to the emergence of road ecology as a specific scientific discipline (Forman et al. 2003). Among available tools, molecular genetic techniques recently emerged as particularly useful to detect road impacts on population structures (Balkenhol and Waits 2009). In close collaboration with local road planners, as recommended in Lesbarreres and Fahrig (2012), we carried out a broad-scale analysis of the potential impacts of two LTIs, a divided highway and a high-speed railway, on spatial genetic patterns in the alpine newt Ichthyosaura alpestris. Many landscape genetic studies assessing the impact of roads on amphibians have detected a decrease in genetic diversity and an increase in genetic differentiation in the vicinity of LTIs (Lesbarreres et al. 2006; Holderegger and Di Giulio 2010; Emel and Storfer 2012), probably resulting in population fragmentation. The alpine newt is no exception, as shown in a recent study in Switzerland (Van Buskirk 2012). Furthermore, both LTIs are located along the ParisLyon axis, a sector already suspected to prevent genetic exchange in another species, the European wildcat Felis silvestris silvestris (Say et al. 2012). We thus expected the two LTIs under study to significantly alter gene flow in the alpine newt: the A6 highway and the LGV-PSE high-speed railway should be associated with a significant increase in genetic distances between individuals located on either side or should coincide with sharp genetic discontinuity between genetic clusters. To test this hypothesis, we used both simulated and empirical genetic data, gathered following a regular individual-based sampling scheme in order to optimize the number of sampled sites across the study area. This kind of 
sampling scheme is a powerful alternative to the conventional population-based sampling scheme, that proved to be particularly efficient at detecting recent barriers to gene flow when designed as a targeted sampling scheme, that is when sampled sites are localized in the direct vicinity of a putative barrier (Anderson et al. 2010; Prunier et al. 2013).

\section{Materials and methods}

\section{Study area}

The study was carried out in eastern central France (Bourgogne), over an area of approximately $60 \mathrm{x}$ $55 \mathrm{~km}$ (Fig. 1a), with elevation ranging from 138 to $857 \mathrm{~m}$ (mean elevation: $399 \mathrm{~m}$ ). This area comprised several water catchments and three distinct landscape entities (Fig. 1b): (1) In the south-west lies Le Morvan, a massif comprising low elevation fragmented wooded patches and extensively pastured meadows for livestock farming, with a dense hydrographic network (minimum elevation: $400 \mathrm{~m}$ ). (2) In the east, L'Auxois is a cultivated plateau in the continuity of Le Morvan, interrupted by two parallel geologic depressions (minimum elevation: 300m). (3) In the north, Terre-Plaine is a vast low-elevation plain (minimum elevation: 187m). Both Terre-Plaine and geologic depressions in L'Auxois are covered with cultivated fields (mainly cereal crops), extensively pastured meadows and wooded patches.

The study area is crossed by two large-scale transportation infrastructures (LTIs) localized along the Paris-Lyon axis: (1) the A6 highway, a divided highway in use since 1969, crosses Terre-Plaine and the eastern geologic depression in L'Auxois; (2) the LGV-PSE high-speed railway, in use since 1981, runs along Le Morvan eastern foothills. These infrastructures were respectively 41 and 29 year-old when the field study was initiated in 2010. For comparison, the oldest road sections studied in Van Buskirk (2012) dated back to 1962 , that is, 38 years before the beginning of sampling.

Both LTIs are approximately $25 \mathrm{~m}$ wide (50 $\mathrm{m}$ wide when considering the fenced area). They are regularly crossed by country roads, tracks and natural streams, with approximately one crossing structures every kilometer. They intersect in Terre-Plaine and delimit four distinct sectors $(A, B, C$ and $D$, Fig. 1a). Except for the two LTIs, artificial areas are mainly composed of farms, villages and a few small towns, all 


\section{Genetic sampling and genotyping} with one pond per $\mathrm{km}^{2}$ on average.

\section{Biological model}

connected by roads with low to medium traffic. The study area includes high densities of aquatic sites,

The alpine newt is a widespread species in central Europe that strongly depends on permanent fish-free ponds or smaller aquatic sites such as ruts, surrounded by suitable terrestrial habitat such as woods and semi-natural grasslands (Joly et al. 2001). In Bourgogne, this amphibian benefits from extensive livestock farming that allows the preservation of many natural or artificial ponds in pastures. The alpine newt is an annual breeder, with reported longevity up to 10 years below $1000 \mathrm{~m}$ of altitude (Miaud et al. 2000; Perret et al. 2003), although skeletochronology of phalanges, the most widely used method of ageing amphibians, has been shown to underestimate the true age of long-lived amphibians (Wagner et al. 2011): in our study area, we may thus expect individuals to live up to 15 or 20 years. Age at maturity is estimated at three year-old at low altitudes (Miaud et al. 2000). Dispersal movements may range from several hundred meters to one kilometer (Joly and Grolet 1996; Denoel 2005; Kovar et al. 2009), although movements up to four kilometers have been reported (Schäfer 1993; Schmidt et al. 2006). While juvenile dispersal is rather the doing of male juveniles (Joly and Grolet 1996), several capturemark-recapture studies also reported high rates of breeding dispersal in both sexes, ranging from 4 to $48 \%$ of dispersal adults per population (depending on landscape configuration; Perret et al. 2003; Schmidt et al. 2006; Kopecky et al. 2010, 2012). This suggests that habitat supplementation is probably as important as habitat complementation in this species (Dunning et al. 1992; Kopecky et al. 2010). This highly nomadic behaviour may lead to strong gene flow and weak genetic differentiation among subpopulations despite distances of up to several kilometers (Emaresi et al. 2011; Van Buskirk 2012; Prunier et al. 2013), especially when high densities of aquatic sites are available, which was the case in our study. The alpine newt thus constitutes a pertinent biological model for the study of barrier effects, since individuals with high dispersal abilities may encounter roads at higher rates than less mobile species, thus shortening the time-lag before barrier detection (Landguth et al. 2010; Prunier et al. 2013). 
(artificial or natural ponds, flooded ruts, swamps, etc.) were prospected with a dip net for thirty to sixty minutes (depending on site size and configuration) or until a male and a female were captured. Using individuals rather than populations as the operational unit proved to be quite efficient at detecting recent barriers to gene flow in previous studies (Landguth et al. 2010; Prunier et al. 2013). It notably allows the number of sampled genotypes per aggregate to be reduced in favour of a better coverage of landscape in the vicinity of both LTIs, thus minimizing the number of unsampled populations (Beerli 2004; Lowe and Allendorf 2010).

Alpine newts were found in 225 sites ( $66 \%$ of prospected sites). The median distance between neighbouring sites (following a Delaunay triangulation) was $2.88 \mathrm{~km}$, ranging from $184 \mathrm{~m}$ to $10.79 \mathrm{~km}$. Non-destructive genetic samples using buccal swabs were taken from each captured individual (Broquet et al. 2007). Samples were stored at ambient temperature in an air-tight container with silica gel providing total desiccation. DNA extraction, PCR amplifications and genotyping were performed as described in Prunier et al. (2012), using 14 autosomal microsatellite loci: CopTa1, CopTa2, CopTa3, CopTa4, CopTa7, CopTa8, CopTa9, CopTa10, CopTa11, CopTa12, CopTa13 and CopTal4 (Prunier et al. 2012), TalCal and TalCaga4 (Garner et al. 2003). Significant gametic disequilibrium was detected between CopTa7, CopTa9 and CopTa10 in a previous study realized at the population-level (Prunier et al. 2012). CopTa7 and CopTa9 were thus discarded from all further analyses except spatial principal component analyses (sPCA; Jombart et al. 2008), as this method is not contingent on any particular genetic model. Neither null alleles nor linkage disequilibrium were detected with this new combination of 12 markers (Prunier et al. 2012). To assess the reliability of our genetic data, we estimated the mean error rate per locus $e_{l}$ (Pompanon et al. 2005) by blind replication of 45 out of 1081 samples (4.2\%) collected from 2009 to 2011 as part of a general research program on the alpine newt. 1996; Kopecky et al. 2012), all the following analyses were performed using males (dataset $M$ ) and females (dataset $F$ ) separately, except when specified. Indeed, provided that only adults are sampled, the use of autosomal nuclear markers does not prevent the detection of sex-specific differences in dispersal (Goudet et al. 2002). 


\section{Isolation-by-distance, isolation-by-resistance and isolation-by-barrier}

Nearest neighbour mating, the standard process driving genetic differentiation among organisms and leading to patterns of isolation-by-distance $I B D$ (Broquet et al. 2006), and landscape fragmentation, leading to patterns such as isolation-by-barrier $I B B$ or isolation-by-resistance $I B R$, may occur simultaneously. It is therefore of crucial importance to test for $I B D$ prior to any other analysis (Schwartz and McKelvey 2009). We performed spatial autocorrelation analyses with non-directional Mantel correlograms (Smouse and Peakall 1999; Borcard and Legendre 2012) to determine the scale $S$ at which $I B D$ patterns occur in each dataset (Epperson 2003). For this purpose, we computed inter-individual pairwise genetic distances using the Bray-Curtis percentage dissimilarity measure as described in Cushman et al. (2006). Euclidean distance classes were defined every $3000 \mathrm{~m}$ (up to $30 \mathrm{~km}$ ), resulting in 10 binary matrices representing the membership of individuals to the distance class being tested (with 0 for pairs of individuals belonging to the same distance class and 1 otherwise). Each binary matrix was compared to the genetic distance matrix using a simple Mantel test with 1000 permutations. We then plotted Mantel correlation values over distance classes, with a 95\% confidence interval determined by bootstrap resampling (1000 iterations).

The two LTIs were expected to act as barriers to gene flow, and the spatial individual-based sampling scheme was specifically designed to test this hypothesis. We thus tried to detect such a signal with a priori knowledge on the location of each putative barrier, using correlative analyses and spatial subsets of datasets $M$ and $F$ with selected genotypes located at least $S \mathrm{~km}$ from each LTI. This targeted sampling scheme was designed to avoid large gaps between sampled points and putative barriers to gene flow (Anderson et al. 2010; Prunier et al. 2013). This procedure resulted in the design of four new datasets: $M_{A 6}, F_{A 6}, M_{L G V-P S E}$ and $F_{L G V-P S E}$. For each dataset, we computed a pairwise genetic distance matrix using the Bray-Curtis percentage dissimilarity measure. The use of inter-individual measures of genetic relatedness is expected to substantially enhance the detection of recent genetic patterns when compared to the use of conventional inter-population genetic distances, as allelic frequencies may suffer from a loss of resolution due to the averaging of genetic information at the population level (Landguth et al. 2010; Prunier et al. 2013): occurrence of alleles in individual genotypes may actually evolve at higher rates than allelic frequencies. For each dataset, we also computed a pairwise Euclidean distance (IBD) matrix and a pairwise $I B B$ distance matrix, coded with 0 when two individuals were located on the same 
217 null hypothesis, competing hypotheses can also be proposed to determine whether genetic structure may

218 be influenced by additional landscape features (e.g. Cushman et al. 2006; Goldberg and Waits 2010), as controlling for IBR may indeed reveal LTI influences otherwise undetected. For each dataset, we thus computed three pairwise $I B R$ distance matrices based on the potential influence of slope (IBR $R_{\text {slope }}$; Murphy et al. 2010; Emel and Storfer 2012), land cover (IBR ${ }_{L C}$; Spear et al. 2005; Goldberg and Waits $2010)$ or a combination of these two features $\left(I B R_{\text {slopeLC }}\right)$. Slope, measured in percent and ranging from 0 to $72 \%$ in the study area, was derived from a 50-m SRTM-Digital Elevation Model (Shuttle Radar

224 Topography Mission). Wood patches and urbanized areas, respectively known to improve and to impede gene flow in the alpine newt (Emaresi et al. 2011), were extracted from national maps (BD Topo from National Geographic Institute, France, 1/25 000). We used ARCGIS 9.3 and its extension SPATIAL ANALYST to manage and rasterize these features. We then used the MATLAB software coding environment (Mathworks, Inc.) to compute least-cost-paths between pairwise individuals (Adriaensen et al. 2003) over three distinct resistance rasters representing: (1) landscape resistance due to slope $\left(I B R_{\text {slope }}\right)$ with grid cell values parameterized according to a linear function $(y=(2 / 72) x+1)$ and ranging from 1 to 3 ; (2) landscape resistance due to land cover $\left(I B R_{L C}\right)$ with grid cell values set to 1 for wooded patches, 3 for urbanized areas and 2 otherwise; (3) landscape resistance due to a combination of these two features $\left(I B R_{\text {slopeLC }}\right)$ and obtained by addition. Using simple and partial Mantel tests in a causal modeling framework (Cushman et al. 2006; Cushman et al. 2013), we first tested for IBD by comparing each pairwise genetic distance matrix to the corresponding Euclidean distance $I B D$ matrix. We then tested for $I B R$ by comparing each pairwise genetic distance matrix to the corresponding $I B R_{\text {slope }}, I B R_{L C}$ and $I B R_{\text {slope } L C}$ distance matrices after controlling for the effect of the $I B D$ matrix. Finally, we tested for $I B B$ by comparing each pairwise genetic distance matrix to the corresponding IBB distance matrix after controlling for the effect of the $I B D$ or the $I B R$ distance matrices. Given the objective of our study and the current controversy regarding the use of Mantel tests in model selection (Graves et al. 2013; Guillot and Rousset 2013), IBR matrices were not used for the selection of alternative scenarios but only to improve barrier detection. coding environment (Mathworks, Inc.). All spatial variables (Euclidean distances and least-cost-paths) 
were log-transformed following the $D=\ln (d+1)$ formula and standardized to meet linearity assumptions.

In order to ensure that $I B B$ detection power was not restricted by a limited number of genotypes, we also

247 performed the same analyses with both males and females located at less than $S \mathrm{~km}$ from each LTI using

248 Mantel tests with 1000 restricted permutations (Prunier et al. 2013).

\section{Genetic structure analyses}

The combination of overlay clustering methods with correlative analyses proved to be particularly powerful in detecting recent barriers to gene flow (Landguth et al. 2010; Safner et al. 2011; Blair et al. 2012). Bayesian clustering algorithms were successfully used in several studies aiming at detecting barriers to dispersal (e.g. Frantz et al. 2012; Hepenstrick et al. 2012). We used TESS 2.3.1 (Chen et al. 2007), a spatial Bayesian clustering method, to identify clusters of individuals. This program computes probabilities that each individual genotype originates from one of $K$ panmictic populations. Accounting for both the putative barrier effect of LTIs segregating the study area in four distinct sectors (Fig. 1a) and the extent of our study area, we did not expect to detect more than ten distinct genetic clusters (one cluster in sector $D$ and three clusters in each sector $A, B$ or $C$ ). Genetic data were analyzed using correlated allele frequencies and other parameters were set to default values. We used the admixture CAR model starting from a neighbour-joining tree based on a Delaunay triangulation (Fig. 1c). Preliminary analyses indicated that setting the spatial interaction parameter to its default value (0.6) was well supported by data. To estimate the true number of genetic clusters $K$, we made five runs per $K$ for $K=2$ to 10 , with 100000 sweeps and a burn-in period of 10000 sweeps. We then identified which value of $K$ produced the highest likelihood runs (lowest values of DIC), and made 100 runs for $K_{\max }$, with the same parameters. The 20 best results (lowest values of DIC) were averaged with CLUMPP (Jakobsson and Rosenberg 2007). To visualize the results, we used the kriging function provided in the $R$-package 'gstat' (Pebesma 2004; $\mathrm{R}$ Development Core Team 2011) to represent the estimated membership of each individual on a grid with a resolution of $500 \mathrm{~m}$, following an inverse distance weighted interpolation function. We also performed a spatial principal component analysis (sPCA; Jombart et al. 2008), a spatiallyexplicit multivariate method using individual genotypes to investigate the spatial patterns of genetic variability. This method, seeking principal components that optimize the variance of individual allelic frequencies while taking spatial autocorrelation of data into account, does not require Hardy-Weinberg or 

the spatial genetic structures. It disentangles global structures, i.e. strong genetic similarity or positive autocorrelation between neighbors, from local ones, i.e. strong genetic differences or negative autocorrelation between neighbors. For each dataset, we used a distance-based neighborhood network with a distance threshold $S$ consistent with Mantel correlograms. A global and a local Monte Carlo test were carried out with 10000 permutations to evaluate the significance of detected patterns (Jombart et al. 2008).

In addition, we evaluated the presence of sharp genetic boundaries with no a priori knowledge on the location of putative barriers using the Monmonier's Maximum Difference Algorithm (Monmonier 1973) implemented in AIS (Miller 2005). This tool did not provide additional information about genetic structure in I. alpestris: methods and results are thus presented in Appendix A.

\section{Simulations}

One of the main issues when trying to detect the impact of roads on gene flow is the time-lag between the creation of infrastructures and the ensuing genetic response (Anderson et al. 2010; Landguth et al. 2010). Simulations were thus performed to determine whether the two LTIs were old enough for possible genetic discontinuities to be detected in our study. For this purpose, we used CDPOP (Landguth and Cushman 2010), a spatially explicit, individual-based cost distance genetic program, to simulate realistic gene flow among aggregates over 200 overlapping generations.

We considered a total of 450 localities, including the 225 sites were alpine newts were actually sampled along with 225 additional fictive sites (Fig. 1a). Resulting densities of simulated sites were four to five times lower than those encountered in the field, but were optimized according to software memory limitations. Each locality was initiated with 10 individuals and kept at a constant size over generations. This low number of individuals per aggregate is realistic when high densities of breeding sites are available. For instance, only six aquatic sites out of 72 allowed the capture of more than 20 individuals in a previous study in Bourgogne (Prunier et al. 2013). The age structure was defined according to a normal distribution with a mean $\mu=0$ and a standard deviation $\sigma=5$ so that the maximal longevity of individuals was 18 years (Appendix B). Age at maturity was fixed at three year-old (Miaud et al. 2000) and both 
males and females were allowed to mate with replacement (Garner and Schmidt 2003; Hoeck and Garner 2007). The simulated number of offspring per mating event was drawn from a Poisson distribution with mean $\lambda=1$, resulting in an average of 4.2 offspring per female and per generation. Although below the reported number of eggs laid by alpine newt females during a single breeding season (between 200 and 300 eggs; Osikowski 2007), this parameter avoided an overproduction of offspring in regard to the total number of available localities at each generation. Offspring sex was randomly assigned following a binomial distribution and an unbiased sex ratio. Genetic polymorphism was defined according to real genetic data, with 12 microsatellite loci and 9 alleles per locus (mean number of alleles per locus in empirical data: 8.67). Genotypes were randomly assigned at the beginning of simulations and the mutation rate was set to 0.0005 , as in Blair et al. (2012).

We simulated mating and dispersal movements so that the resulting scale of $I B D$ matches with the observed scale $S$ of $I B D$ in empirical datasets. According to preliminary analyses using non-directional Mantel correlograms as described above, travelled distances were drawn from a probability distribution inversely proportional to a linear function, with the maximal dispersal cost distance that may be travelled (associated with a null probability; Landguth and Cushman 2010) set to $3000 \mathrm{~m}$ (Fig. 2c).

Cost distances were based on Euclidean distances between pairwise aggregates. We investigated the time-lag between the creation of both LTIs and the ensuing simulated genetic response by respectively placing the A6 highway and the LGV-PSE railway as impermeable barriers to dispersal at generations 100 (thus corresponding to year 1969) and 112 (thus corresponding to year 1981). We replicated the simulation 10 times to account for demographic stochasticity.

For each replicate, individual genotypes were collected from generation 100 to 200 with an increment of 5 . Using only the 225 aggregates corresponding to real aquatic sites in the empirical dataset, we randomly subsampled two individuals per aggregate and computed pairwise genetic distances using the Bray-Curtis percentage dissimilarity measure, as described above. We repeated this subsampling procedure 10 times to account for sampling stochasticity, resulting in a total of 100 genetic matrices per generation. We then used partial Mantel tests with 1000 restricted permutations (Prunier et al. 2013) to test for the effects of the highway and the railway while controlling for $I B D$. Mantel correlations were averaged across all replicates and all subsampling schemes. We finally plotted the averaged Mantel correlation values over generations, with a $95 \%$ confidence interval determined by bootstrap resampling 
(1000 iterations). We considered that a barrier effect was detectable when at least $95 \%$ of partial Mantel tests were significant $(\mathrm{P}$-value $\leq 0.05)$.

\section{Results}

\section{Simulations}

Simulations were performed with $3000 \mathrm{~m}$ as the maximal distance that may be travelled by juveniles for dispersal and adults for mating. On average, this parameter led to dispersal and mating movements of $1238 \mathrm{~m}$ long $( \pm 1000 \mathrm{~m})$ and to annual mean dispersal rates of $14.5 \%$ (1.45 dispersal events per year and per population). Mantel correlograms showed significant genetic relatedness between pairwise individuals for the first $12 \mathrm{~km}$ (first 4 bins), and either no or negative autocorrelation as distance increased (Fig. 2c). When simulated as totally impermeable, the A6 highway and the LGV-PSE railway were respectively detected as significant barriers to gene flow after 35 and 58 years, that is approximately 11 and 19 generations (Fig. 5). Interestingly, time-lag before detection of a significant barrier effect was longer for the railway than the highway, suggesting that the spatial distribution of sampling points directly influences the detection power of genetic discontinuities in correlative analyses. According to these results, only the highway was old enough for a significant barrier effect to be detected in our study (Fig. 5).

\section{Genetic data}

A total of 417 individuals (206 Males, dataset $M$, and 211 females, dataset $F$ ) were sampled in the study area. Both a male and a female were captured in 192 ponds, from a total of 225 ponds where I. alpestris was detected. The mean number of genotypes per site was 1.85 . The genotyping error rate, estimated by blind replications as the mean error rate per locus $e_{l}$, was less than $2.4 \%$ in CopTa1, CopTa4, CopTal4 and TalCaga4, and $0 \%$ for the 10 other loci.

\section{Isolation-by-distance, isolation-by-resistance and isolation-by-barrier}

In both empirical datasets, Mantel correlograms showed significant genetic relatedness between pairwise individuals for the first $12 \mathrm{~km}$ (first 4 bins), and either no or negative autocorrelation as distance 

$I B D$ process over the study area. However, correlation values in the first distance classes were not as high

362

\section{Genetic structure} and did not show any regular decrease as in simulated data. This may be due to the presence of higher densities of aquatic sites in the study area than simulated in CDPOP, allowing a better spread of alleles at close distances. The spatial scale of genetic autocorrelation $(S=12 \mathrm{~km})$ was similar in males and females. Selecting individuals located at less than $S=12 \mathrm{~km}$ from each infrastructure allowed the design of four new datasets $\left(M_{A 6}, F_{A 6}, M_{L G V-P S E}\right.$ and $\left.F_{L G V-P S E}\right)$ with at least 153 genotypes each (Table 1). A significant $I B D$ was detected in each dataset (Table 1). Except in $M_{A 6}$ dataset, in which case the effect of land cover as described in Emaresi et al. (2011) was close to significance, neither IBR nor IBB was ever detected whatever the dataset or the considered IBR scenario (Table 1). In the case of IBB detection, Mantel correlation values were always negative in $M_{A 6}$ and $F_{A 6}$ datasets and positive in $M_{L G V-P S E}$ and $F_{L G V-P S E}$ datasets. The same results were obtained when using both males and females data (data not shown). to detect any genetic structure (data not shown), which may be explained by the low number of genotypes in each dataset. We thus combined males and females data. The best estimate of the number of clusters using the averaged DIC criterion over the five runs performed per $K$ was 3 (Fig. 3a). However, runs performed for $K_{\max }=3$ showed high variability in DIC values. Furthermore, for $K_{\max }>2$, the posterior estimates of cluster membership for each individual systematically displayed only one or two clusters, the additional clusters containing negligible proportions. We thus performed 100 runs with $K_{\max }=2$. This number of inferred clusters allowed the use of a simple kriging interpolation function. The 20 best runs averaged using CLUMPP led to the progressive discrimination of individuals in two clusters (Fig. 3b): according to figure 3c, individuals with an estimated membership in cluster 1 higher than $40 \%$ were located in Terre-Plaine, while those with a lower estimated membership were located in Le Morvan and L'Auxois. Although most individuals had high probability of assignment to one cluster or the other, high levels of admixture were encountered at the interface of these two clusters, confirming the existence of an $I B D$ pattern. The detected boundary was not related to the presence of LTIs. 
$10^{4}$; dataset $\left.F, \max (t)=0.011, p<10^{4}\right)$, indicating the presence of significant global genetic structures in all datasets. On the contrary, local Monte-Carlo tests did not detect any significant local structure (dataset $M, \max (t)=0.007, N S ;$ dataset $F, \max (t)=0.006, N S)$. The analyses revealed four kinds of global genetic patterns (Fig. 4e). In both datasets, scores of individuals along the first sPCA axis distinguished TerrePlaine from the rest of the study area, as did TESS (Fig. 4a, Boundary I). A second pattern was revealed by second sPCA scores in dataset $M$ (Fig. 4b): this structure clearly segregated individuals located in $L e$ Morvan from the rest of the study area (Boundary II); a third group, identified in the west of Terre-Plaine (Boundary III) corresponded to the westernmost water catchment in Terre-Plaine, although further analyses, performed over a more extended study area, may be required to confirm this pattern. Scores of females along the second SPCA axis (dataset $F$ ) revealed a slightly different pattern in the south, with higher genetic similarity among individuals located in southern hilly landscapes from Le Morvan and L'Auxois (Fig. 4c, southern white squares, Boundary IV). Finally, third sPCA scores in females (Fig. 4d) displayed a pattern highly similar to the one obtained from the second sPCA scores in dataset $M$ (Boundary II). However, females from Terre-Plaine located next to the highway showed higher scores than females located more distantly (area delimited with white dashes), indicating higher genetic similarity among individuals in the direct vicinity of the highway. Boundaries $I I$ and $I V$ in females were also identified as sharp boundaries by Monmonier's algorithm (see Appendix A). LTIs never separated inferred groups.

407

\section{Discussion}

Our study was based on an individual-based targeted sampling scheme in a highly mobile species

411 and was thus designed to optimize barrier detection. However, while simulations provided good insight 412 into the temporal scale before barrier detection in our study and suggested that the A6 highway was old enough for a significant barrier effect to be detected, inferred spatial genetic patterns did not support this

414 hypothesis. Indeed, the LTIs were never detected as barriers to gene flow, observed genetic boundaries rather coinciding with transition zones between major landscape entities. 
$417 I B D$ patterns in simulated data, with dispersal rates and travelled distances in the range of empirical 418 observations reported in the literature (Joly and Grolet 1996; Perret et al. 2003; Schmidt et al. 2006; 419 Kopecky et al. 2010; Fig. 2c). Despite the use of overlapping generations, both simulated LTIs were 420 detected as significant barriers to gene flow in less than 20 generations, as already observed in Landguth et al. (2010) with correlative analyses (Fig. 5). However, considering the time-lag between the creation of

422 LTIs and the beginning of genetic sampling, the LGV-PSE high-speed railway was probably too recent for a significant barrier effect to be detected in our study.

A significant $I B D$ pattern was detected in both sexes in empirical data, with higher genetic relatedness among individuals less than $12 \mathrm{~km}$ apart. The detection of this long-distance $I B D$ pattern in $I$. alpestris is consistent with previous studies (Perret et al. 2003; Pabijan and Babik 2006; Emaresi et al. 2011; Prunier et al. 2013) and suggests that genes spread out according to a 'stepping-stone' model (Kimura and Weiss 1964), high densities of aquatic sites in the study area allowing alpine newts to perform several discrete dispersal movements between neighbouring ponds throughout their lifetime (Semlitsch 2008). This pattern also reinforced the expectation of significant barrier detection in this species. Highly nomadic individuals may actually encounter roads at higher rates than less mobile ones, thus possibly shortening the period of time until barrier detection (Landguth et al. 2010; Blair et al. 2012; Prunier et al. 2013). Indeed, simulations showed that the A6 highway may have been detected as a total barrier to gene flow in no more than 35 years (approximately 11 generations), despite high longevity and overlapping generations in the alpine newt. However, this LTI was never detected as a barrier to gene flow, whatever the approach. sPCA (Fig. 4a) as well as with TESS (Fig. 3), explained most of the spatial and genetic variability in all datasets (Fig. 4e). Boundaries II and $I V$ (Fig. 4b, c and d) were not detected by TESS but were identified as sharp boundaries by Monmonier's algorithm applied to females (see Appendix A). These patterns coincided with transition zones between major landscape entities in the study area (Fig. 1b and Fig. 4), while the A6 highway and the LGV-PSE high-speed railway were always embedded in inferred clusters. Boundaries I and II respectively distinguished Terre-Plaine and Le Morvan as two distinct homogeneous clusters. In females, boundary $I V$ assigned individuals located in southern higher elevation areas from $L e$ 

with subtle modifications in landscape characteristics such as elevation (Boundaries $I I$ and $I V$ ), land use

447 (Boundaries $I, I I$ and $I V$ ), proportions of wooded patches (Boundary $I I$ ), hydrologic networks (Boundary III), or most probably a combination of these factors. This complexity, as well as the use of a targeted sampling scheme designed to specifically assess the influence of LTIs on gene flow (Prunier et al. 2013), may explain why $I B R$ scenarios, based on simple hypotheses regarding the influence of landscape on gene flow, were not better supported than $I B D$ scenario. More complex scenarios and alternative statistical approaches (Selkoe et al. 2010; Van Strien et al. 2012) may be needed to confirm the observed genetic structure and identify all its possible drivers. Nevertheless, controlling for $I B D$ or $I B R$ did not improve $I B B$ detection. due to the use of too few (or too little variable) microsatellite markers (Landguth et al. 2012). However, simulation results suggested that this number of markers was not a limiting factor in our case. A second explanation may be the time-lag between the processes that caused the formation of spatial genetic structure and the observed spatial genetic structure itself (Landguth et al. 2010). This time-lag may be lengthened by the presence of large effective population sizes on each side of infrastructures (Gauffre et al. 2008), as populations separated by a barrier may still be functionally connected with populations in their hinterland, thus rendering genetic barrier effects difficult to detect. Our study was precisely designed to reduce this time-lag: 1) by considering a species with relatively long range mating and dispersal (Landguth et al. 2010), 2) by using an individual-based sampling scheme and by computing genetic distances based on inter-individual measures of genetic relatedness rather than on conventional interpopulation measures of genetic differentiation (Landguth et al. 2010; Prunier et al. 2013), and 3) by using a targeted sampling design so as to avoid large gaps between sampled points and putative barriers to gene flow (Anderson et al. 2010; Prunier et al. 2013). Our simulation results, showing that no more than 35 years would be necessary for the A6 highway to be detected as totally impermeable to dispersal (Fig. 5) despite the simulation of gene flow among 450 highly connected fictive aggregates (Fig. 1a), suggest indeed that our study was not susceptible to this issue, at least in the case of the A6 highway. of the railway (although field observations suggested that newts may be able to move underneath rail 
tracks). But interestingly, although both LTIs were similarly simulated as total barriers to gene flow, 58 years (approximately 19 generations) were necessary for the detection of the railway as a barrier, as opposed to 35 years in the case of the highway (Fig. 5). This result suggests that the spatial distribution of aggregates in the vicinity of LTIs, and possibly the layout of LTIs itself, may directly influence the timelag before barrier detection, highlighting the need for a case-by-case study of roads effects on wildlife. Contrary to the LGV-PSE high-speed railway, several clues apart from simulations allow us to reasonably assume that the A6 highway may simply be permeable to gene flow. Firstly, investigating the barrier effect of the A6 highway using correlative analyses led to systematic negative Mantel correlations (Table 1). This pattern may need further investigations to be fully explained, although such negative Mantel correlations were already observed between independent variables in Dutilleul et al. (2000). In any case, observed correlations in $I B B$ analyses were far from being positive, suggesting that transverse gene flow was definitely not affected by the A6 highway. Secondly, the detection of a longitudinal genetic pattern in SPCA results, with higher genetic similarity among females located in the direct vicinity of the highway (Figure 4d), suggests that this infrastructure is not only permeable to gene flow, but also that it may serve as a longitudinal dispersal corridor in a low-quality matrix such as Terre-Plaine, characterized by high proportions of fragmented wooded patches and cultivated crops (Fig. 1a; Meunier et al. 1999; Tikka et al. 2001). This counterintuitive genetic pattern was only detected with the third sPCA axis, suggesting that it may be the result of recent landscape changes when compared to the main genetic structure coinciding with major historical landscape entities. Direct approaches such as telemetry or capture-mark-recapture protocols will be necessary to confirm this hypothesis. However, this pattern is consistent with sex-biased dispersal abilities observed in the alpine newt: females being less mobile than males at the juvenile stage (Joly and Grolet 1996; Perret et al. 2003), they may benefit from the existence of both evenly-spaced transverse passages (e.g. culverts, extended stream crossings or dirt roads; Lesbarreres et al. 2004; Lesbarreres and Fahrig 2012) and favorable roadside structures (e.g. ditches for rainwater drainage or stormwater retention ponds; Le Viol et al. 2012) to disperse through and along the highway. This phenomenon may be facilitated by the water filling of such structures during rainfall events (Schalk and Luhring 2010), notably in sectors that are highly resistant to movements such as agricultural plains (Joly et al. 2001; Janin et al. 2009; Cosentino et al. 2011). 
503 Hepenstrick et al. 2012) and corridors for alien ones (Trombulak and Frissell 2000; Tikka et al. 2001;

504 Von der Lippe and Kowarik 2007). For instance, drainage ditches along highways may provide suitable 505 conditions for the establishment and the spread of aquatic invaders such as the common reed Phragmites 506 australis in North America (Jodoin et al. 2008; Brisson et al. 2010). Road verges may also facilitate 507 dispersal in ground-dwelling exotic species such as the cane toad Bufo marinus in Australia (Brown et al. 508 2006). However, roads may also facilitate dispersal of native species, as recently shown in the lizard 509 Gallotia galloti in Canari islands (Garcia et al. 2007). Although we still have to demonstrate that 510 transverse and roadside structures are effectively used by dispersing individuals, our results revealing that 511 the alpine newt is not affected by and may even benefit from the presence of the A6 highway suggest that

512 LTIs do not necessarily lead to systematic conservation issues, as an increase in dispersal abilities of 513 native species is a key parameter in the context of landscape fragmentation and climate change (Bonte et 514 al. 2012). However, these results are specific to the highway under study, as any road in a different 515 environmental context may hinder genetic exchanges in the alpine newt (e.g. Van Buskirk 2012):

516 Considering local interactions between species, infrastructures and landscape-specific characteristics 517 proves to be essential for a better understanding of the potential impacts of LTIs on movement patterns in 518 terrestrial organisms (Balkenhol and Waits 2009; Knapp et al. 2013). Further investigations are thus 519 required to define species-specific benchmarks in terms of permeability of road structures (and road 520 design) to movements (Mata et al. 2008; Woltz et al. 2008; Lesbarreres and Fahrig 2012), and to clarify the impact of land use conversion in the vicinity of various LTIs (or sections of LTIs).

522

\section{Acknowledgements}

524 This work was supported by the Agence Nationale de la Recherche et de la Technologie (ANRT, 525 agreement 22009), Réseau Ferré de France (RFF), Autoroutes Paris-Rhin-Rhône (APRR) and the 526 ECOSPHERE company. It was conducted in accordance with French laws and with the approval of the 527 Préfectures de Saône-et-Loire, de Côte-d'Or and de l'Yonne. We warmly thank T. Jombart for helpful comments about sPCA results, P. Allemand for his help in Matlab programing, E. Landguth for clues as

529 to the use of CDPOP and J. Van Buskirk for details about its own study. In addition, we thank C. De 530 Fazio, G. Perez, F. Revollon, F. Ribette, J. Mangin and O. Grolet for their precious help and support in 
531 the field and laboratory, Anne Corrigan for proofreading, and two anonymous reviewers for

532 comments that greatly improved this manuscript.

533

534 Electronic supplementary material

535 Supplementary data associated with this article can be found in the online version.

536 
537

538

539

540

541

542

543

544

545

546

547

548

549

550

551

552

553

554

555

556

557

558

559

560

561

562

563

564

565

566

\section{References}

Adriaensen F, Chardon JP, De Blust G, Swinnen E, Villalba S, Gulinck H, Matthysen E (2003) The application of 'least-cost' modelling as a functional landscape model. Landscape Urban Plan 64 (4):233-247. doi:10.1016/s0169-2046(02)00242-6

Anderson CD, Epperson BK, Fortin MJ, Holderegger R, James PMA, Rosenberg MS, Scribner KT, Spear S (2010) Considering spatial and temporal scale in landscape-genetic studies of gene flow. Mol Ecol 19 (17):3565-3575. doi:10.1111/j.1365-294X.2010.04757.x

Balkenhol N, Waits LP (2009) Molecular road ecology: exploring the potential of genetics for investigating transportation impacts on wildlife. Mol Ecol 18 (20):4151-4164. doi:10.1111/j.1365-294X.2009.04322.x

Bartoszek J, Greenwald KR (2009) A population divided: railroad tracks as barriers to gene flow in an isolated population of marbled salamanders (Ambystoma opacum). Herpetol Conserv Biol 4 (2):191-197

Beebee TJC (2013) Effects of Road Mortality and Mitigation Measures on Amphibian Populations. Conserv Biol 27 (4):657-668. doi:10.1111/cobi.12063

Beerli P (2004) Effect of unsampled populations on the estimation of population sizes and migration rates between sampled populations. Mol Ecol 13 (4):827-836. doi:10.1111/j.1365-294X.2004.02101.x

Blair C, Weigel DE, Balazik M, Keeley ATH, Walker FM, Landguth E, Cushman S, Murphy M, Waits L, Balkenhol N (2012) A simulation-based evaluation of methods for inferring linear barriers to gene flow. Mol Ecol Resour 12 (5):822-833. doi:10.1111/j.1755-0998.2012.03151.x

Bonte D, Van Dyck H, Bullock JM, Coulon A, Delgado M, Gibbs M, Lehouck V, Matthysen E, Mustin K, Saastamoinen M, Schtickzelle N, Stevens VM, Vandewoestijne S, Baguette M, Barton K, Benton TG, ChaputBardy A, Clobert J, Dytham C, Hovestadt T, Meier CM, Palmer SCF, Turlure C, Travis JMJ (2012) Costs of dispersal. Biol Rev 87:290-312. doi:10.1111/j.1469-185X.2011.00201.x

Borcard D, Legendre P (2012) Is the Mantel correlogram powerful enough to be useful in ecological analysis? A simulation study. Ecology 93 (6):1473-1481

Brisson J, de Blois S, Lavoie C (2010) Roadside as invasion pathway for common reed (Phragmites australis). Invasive Plant Sci Manag 3 (4):506-514. doi:10.1614/ipsm-09-050.1

Broquet T, Berset-Braendli L, Emaresi G, Fumagalli L (2007) Buccal swabs allow efficient and reliable microsatellite genotyping in amphibians. Conserv Genet 8 (2):509-511. doi:10.1007/s10592-006-9180-3

Broquet T, Ray N, Petit E, Fryxell JM, Burel F (2006) Genetic isolation by distance and landscape connectivity in the American marten (Martes americana). Landscape Ecol 21 (6):877-889. doi:10.1007/s10980-005-5956-y 

toads (Bufo marinus) at an invasion front in tropical Australia. Biol Cons 133 (1):88-94. doi:10.1016/j.biocon.2006.05.020

Chen C, Durand E, Forbes F, Francois O (2007) Bayesian clustering algorithms ascertaining spatial population structure: a new computer program and a comparison study. Mol Ecol Notes 7 (5):747-756. doi:10.1111/j.14718286.2007.01769.x

Cosentino BJ, Schooley RL, Phillips CA (2011) Connectivity of agroecosystems: dispersal costs can vary among crops. Landscape Ecol 26 (3):371-379. doi:10.1007/s10980-010-9563-1

575 Cushman SA, McKelvey KS, Hayden J, Schwartz MK (2006) Gene flow in complex landscapes: Testing multiple hypotheses with causal modeling. Am Nat 168 (4):486-499

Cushman SA, Wasserman TN, Landguth EL, Shirk AJ (2013) Re-evaluating causal modeling with Mantel tests in landscape genetics. Diversity 5 (1):51-72. doi:doi:10.3390/d5010051

Denoel M (2005) Persistence and dispersion of an introduced population of Alpine Newt (Triturus alpestris) in the limestone plateau of Larzac (Southern France). Revue d'Ecologie-La Terre et la Vie 60:139-148

Dodd CK, Barichivich WJ, Smith LL (2004) Effectiveness of a barrier wall and culverts in reducing wildlife mortality on a heavily traveled highway in Florida. Biol Cons 118 (5):619-631. doi:10.1016/j.biocon.2003.10.011

Drescher K, Henderson J, McNamara K Farmland prices determinants. In: American Agricultural Economics Association Annual Meeting, Chicago, Illinois, 2001.

Dunning JB, Danielson BJ, Pulliam HR (1992) Ecological processes that affect populations in complex landscapes.

588 Dutilleul P, Stockwell JD, Frigon D, Legendre P (2000) The Mantel test versus Pearson's correlation analysis: 

and cause a rapid decline in genetic diversity of desert bighorn sheep. Ecol Lett 8 (10):1029-1038. doi:10.1111/j.1461-0248.2005.00804.x

600

Forman RTT, Sperling D, Bissonette JA, Clevenger AP, Cutshall CD, Dale VH, Fahrig L, France R, Goldman CR,

601

602 Heanue K, Jones JA, Swanson FJ, Turrentine T, Winter TC (2003) Road Ecology. Science and Solutions. Island Press, Washington D.C.

604

Frantz AC, Bertouille S, Eloy MC, Licoppe A, Chaumont F, Flamand MC (2012) Comparative landscape genetic

605 analyses show a Belgian motorway to be a gene flow barrier for red deer (Cervus elaphus), but not wild boars (Sus scrofa). Mol Ecol 21 (14):3445-3457. doi:10.1111/j.1365-294X.2012.05623.x

607

Garcia JDD, Arevalo JR, Fernandez-Palacios JM (2007) Road edge effect on the abundance of the lizard Gallotia galloti (Sauria : Lacertidae) in two Canary Islands forests. Biodivers Conserv 16 (10):2949-2963.

608 doi:10.1007/s10531-007-9154-x

609

Garner TWJ, Schmidt BR (2003) Relatedness, body size and paternity in the alpine newt, Triturus alpestris.

610 Proceedings of the Royal Society of London Series B-Biological Sciences 270 (1515):619-624. doi:10.1098/rspb.2002.2284

Garner TWJ, Schmidt BR, Hoeck P, Van Buskirk J (2003) Di- and tetranucleotide microsatellite markers for the Alpine newt (Triturus alpestris): characterization and cross-priming in five congeners. Mol Ecol Notes 3 (2):186-188. doi:10.1046/j.1471-8286.2003.00394.x

Gauffre B, Estoup A, Bretagnolle V, Cosson JF (2008) Spatial genetic structure of a small rodent in a heterogeneous landscape. Mol Ecol 17 (21):4619-4629. doi:10.1111/j.1365-294X.2008.03950.x

Goldberg CS, Waits LP (2010) Comparative landscape genetics of two pond-breeding amphibian species in a highly modified agricultural landscape. Mol Ecol 19 (17):3650-3663. doi:10.1111/j.1365-294X.2010.04673.x

Goudet J, Perrin N, Waser P (2002) Tests for sex-biased dispersal using bi-parentally inherited genetic markers. Mol Ecol 11 (6):1103-1114. doi:10.1046/j.1365-294X.2002.01496.x

Graves TA, Beier P, Royle JA (2013) Current approaches using genetic distances produce poor estimates of landscape resistance to interindividual dispersal. Mol Ecol 22 (15):3888-3903. doi:10.1111/mec.12348 doi:10.1111/2041-210x.12018

625 Hepenstrick D, Thiel D, Holderegger R, Gugerli F (2012) Genetic discontinuities in roe deer (Capreolus capreolus) coincide with fenced transportation infrastructure. Basic Appl Ecol 13 (7):631-638. doi:10.1016/j.baae.2012.08.009 
Hoeck PEA, Garner TWJ (2007) Female alpine newts (Triturus alpestris) mate initially with males signalling fertility benefits. Biol J LinnSoc 91 (3):483-491

Holderegger R, Di Giulio M (2010) The genetic effects of roads: A review of empirical evidence. Basic Appl Ecol 11 (6):522-531. doi:10.1016/j.baae.2010.06.006

Jakobsson M, Rosenberg NA (2007) CLUMPP: a cluster matching and permutation program for dealing with label switching and multimodality in analysis of population structure. Bioinformatics 23 (14):1801-1806. doi:10.1093/bioinformatics/btm233

Janin A, Lena JP, Ray N, Delacourt C, Allemand P, Joly P (2009) Assessing landscape connectivity with calibrated cost-distance modelling: predicting common toad distribution in a context of spreading agriculture. J Appl Ecol 46 (4):833-841. doi:10.1111/j.1365-2664.2009.01665.x

Jodoin Y, Lavoie C, Villeneuve P, Theriault M, Beaulieu J, Belzile F (2008) Highways as corridors and habitats for the invasive common reed Phragmites australis in Quebec, Canada. J Appl Ecol 45 (2):459-466. doi:10.1111/j.1365-2664.2007.01362.x

Joly P, Grolet O (1996) Colonization dynamics of new ponds, and the age structure of colonizing Alpine newts, Triturus alpestris. Acta Oecol 17 (6):599-608

Joly P, Miaud C (1993) How does a newt find its pond - the role of chemical cues in migrating newts (Triturus alpestris). Ethol Ecol Evol 5 (4):447-455

Joly P, Miaud C, Lehmann A, Grolet O (2001) Habitat matrix effects on pond occupancy in newts. Conserv Biol 15 (1):239-248

Jombart T, Devillard S, Dufour AB, Pontier D (2008) Revealing cryptic spatial patterns in genetic variability by a new multivariate method. Heredity 101 (1):92-103. doi:10.1038/hdy.2008.34

649 Kimura M, Weiss GH (1964) The stepping stone model of population structure and the decrease of genetic correlation with distance. Genetics 49 (4):561-576

Knapp M, Saska P, Knappova J, Vonicka P, Moravec P, Kurka A, Andel P (2013) The habitat-specific effects of highway proximity on ground-dwelling arthropods: Implications for biodiversity conservation. Biol Cons 164:22-29. doi:10.1016/j.biocon.2013.04.012

654 Kopecky O, Vojar J, Denoel M (2010) Movements of Alpine newts (Mesotriton alpestris) between small aquatic habitats (ruts) during the breeding season. Amphib Reptil 31 (1):109-116 Mesotriton alpestris (LAURENTI, 1768), among breeding sites (Caudata: Salamandridae). Herpetozoa 24 (3- 
Kovar R, Brabec M, Vita R, Bocek R (2009) Spring migration distances of some Central European amphibian species. Amphib Reptil 30 (3):367-378

Kuehn R, Hindenlang KE, Holzgang O, Senn J, Stoeckl B, Sperisen C (2007) Genetic effect of transportation infrastructure on roe deer Populations (Capreolus capreolus). J Hered 98 (1):13-22. doi:10.1093/jhered/es1056

Landguth EL, Cushman SA (2010) CDPOP: A spatially explicit cost distance population genetics program. Mol Ecol Resour 10 (1):156-161. doi:10.1111/j.1755-0998.2009.02719.x

Landguth EL, Cushman SA, Schwartz MK, McKelvey KS, Murphy M, Luikart G (2010) Quantifying the lag time to detect barriers in landscape genetics. Mol Ecol 19 (19):4179-4191. doi:10.1111/j.1365-294X.2010.04808.x

Landguth EL, Fedy BC, Oyler-McCance SJ, Garey AL, Emel SL, Mumma M, Wagner HH, Fortin MJ, Cushman SA (2012) Effects of sample size, number of markers, and allelic richness on the detection of spatial genetic pattern. Mol Ecol Resour 12 (2):276-284. doi:10.1111/j.1755-0998.2011.03077.x

Le Viol I, Chiron F, Julliard R, Kerbiriou C (2012) More amphibians than expected in highway stormwater ponds.

$$
\text { Ecol Eng 47:146-154 }
$$

Lesbarreres D, Fahrig L (2012) Measures to reduce population fragmentation by roads: what has worked and how do we know? Trends Ecol Evol 27 (7):347-380

Lesbarreres D, Lode T, Merila J (2004) What type of amphibian tunnel could reduce road kills? Oryx 38 (2):220-223. doi:10.1017/s0030605304000389

Lesbarreres D, Primmer CR, Lode T, Merila J (2006) The effects of 20 years of highway presence on the genetic structure of Rana dalmatina populations. Ecoscience 13 (4):531-538

Lowe WH, Allendorf FW (2010) What can genetics tell us about population connectivity? Mol Ecol 19 (15):30383051. doi:10.1111/j.1365-294X.2010.04688.x

Mata C, Hervas I, Herranz J, Suarez F, Malo JE (2008) Are motorway wildlife passages worth building? Vertebrate use of road-crossing structures on a Spanish motorway. J Environ Manage 88 (3):407-415. doi:10.1016/j.jenvman.2007.03.014

McGregor RL, Bender DJ, Fahrig L (2008) Do small mammals avoid roads because of the traffic? J Appl Ecol 45 (1):117-123. doi:10.1111/j.1365-2664.2007.01403.x

Meunier FD, Verheyden C, Jouventin P (1999) Bird communities of highway verges: Influence of adjacent habitat and roadside management. Acta Oecol 20 (1):1-13. doi:10.1016/s1146-609x(99)80010-1

Miaud C, Guyetant R, Faber H (2000) Age, size, and growth of the alpine newt, Triturus alpestris (Urodela : Salamandridae), at high altitude and a review of life-history trait variation throughout its range. Herpetologica 56 (2):135-144 
Miller MP (2005) Alleles In Space (AIS): Computer software for the joint analysis of interindividual spatial and genetic information. J Hered 96 (6):722-724. doi:10.1093/jhered/esi119

Monmonier M (1973) Maximum-difference barriers: An alternative numerical regionalization method. Geogr Anal 5 (3):245-261

Murphy MA, Dezzani R, Pilliod DS, Storfer A (2010) Landscape genetics of high mountain frog metapopulations. Mol Ecol 19 (17):3634-3649. doi:10.1111/j.1365-294X.2010.04723.x

Osikowski A (2007) Sperm transport after insemination in the Alpine newt (Triturus alpestris, Caudata, Salamandridae). Folia Biol-Krakow 55 (3-4):109-114

Pabijan M, Babik W (2006) Genetic structure in northeastern populations of the Alpine newt (Triturus alpestris): evidence for post-Pleistocene differentiation. Mol Ecol 15 (9):2397-2407. doi:10.1111/j.1365294X.2006.02954.x

Pebesma EJ (2004) Multivariable geostatistics in S: the gstat package. Computers \& Geosciences 30:683-691

Perret N, Pradel R, Miaud C, Grolet O, Joly P (2003) Transience, dispersal and survival rates in newt patchy populations. J Anim Ecol 72 (4):567-575

Pompanon F, Bonin A, Bellemain E, Taberlet P (2005) Genotyping errors: Causes, consequences and solutions. Nat Rev Genet 6 (11):847-859. doi:10.1038/nrg1707

Prunier J, Kaufmann B, Grolet O, Picard D, Pompanon F, Joly P (2012) Skin swabbing as a new efficient DNA sampling technique in amphibians, and 14 new microsatellite markers in the alpine newt (Ichthyosaura alpestris). Mol Ecol Resour 12 (3):524-531. doi:10.1111/j.1755-0998.2012.03116.x

Prunier JG, Kaufmann B, Fenet S, Picard D, Pompanon F, Joly P, Lena JP (2013) Optimizing the trade-off between spatial and genetic sampling efforts in patchy populations: towards a better assessment of functional connectivity using an individual-based sampling scheme. Mol Ecol 22 (22):5516-5530

R Development Core Team (2011) R: A Language and Environment for Statistical Computing. R Foundation for Statistical Computing

Riley SPD, Pollinger JP, Sauvajot RM, York EC, Bromley C, Fuller TK, Wayne RK (2006) A southern California freeway is a physical and social barrier to gene flow in carnivores. Mol Ecol 15 (7):1733-1741. doi:10.1111/j.1365-294X.2006.02907.x

Safner T, Miller MP, McRae BH, Fortin M-J, Manel S (2011) Comparison of Bayesian Clustering and Edge Detection Methods for Inferring Boundaries in Landscape Genetics. International Journal of Molecular Sciences 12 (2):865-889. doi:10.3390/ijms 12020865

Say L, Devillard S, Léger F, Pontier D, Ruette S (2012) Distribution and spatial genetic structure of European wildcat in France. Animal Conservation 15:18-27 
Schäfer H-J (1993) Ausbreitung und Entwicklung von Amphibien-Populationen in der Agrarlandschaft. Universität Bonn, Bonn

Schalk CM, Luhring TM (2010) Vagility of Aquatic Salamanders: Implications for Wetland Connectivity. J Herpetol 44 (1):104-109

Schmidt P, Weddeling K, Thomas M, Rottscheidt R, Tarkhnishvili DN, Hachtel M (2006) Dispersal of Triturus alpestris and T. vulgaris in agricultural landscapes - comparing estimates from allozyme markers and capturemark-recapture analysis. Paper presented at the 13th Congress of the Societas Europaea Herpetologica, Bonn, Germany,

Schwartz MK, McKelvey KS (2009) Why sampling scheme matters: the effect of sampling scheme on landscape genetic results. Conserv Genet 10 (2):441-452. doi:10.1007/s10592-008-9622-1

Selkoe KA, Watson JR, White C, Ben Horin T, Iacchei M, Mitarai S, Siegel DA, Gaines SD, Toonen RJ (2010) Taking the chaos out of genetic patchiness: seascape genetics reveals ecological and oceanographic drivers of genetic patterns in three temperate reef species. Mol Ecol 19 (17):3708-3726. doi:10.1111/j.1365294X.2010.04658.x

Semlitsch RD (2008) Differentiating migration and dispersal processes for pond-breeding amphibians. J Wildl Manage 72 (1):260-267. doi:10.2193/2007-082

Smouse PE, Peakall R (1999) Spatial autocorrelation analysis of individual multiallele and multilocus genetic structure. Heredity 82:561-573

Spear SF, Peterson CR, Matocq MD, Storfer A (2005) Landscape genetics of the blotched tiger salamander (Ambystoma tigrinum melanostictum). Mol Ecol 14 (8):2553-2564. doi:10.1111/j.1365-294X.2005.02573.x

Tikka PM, Hogmander H, Koski PS (2001) Road and railway verges serve as dispersal corridors for grassland plants. Landscape Ecol 16 (7):659-666

Trombulak SC, Frissell CA (2000) Review of ecological effects of roads on terrestrial and aquatic communities. Conserv Biol 14 (1):18-30. doi:10.1046/j.1523-1739.2000.99084.x

Van Buskirk J (2012) Permeability of the landscape matrix between amphibian breeding sites. Ecol Evol 2 (12):31603167. doi:10.1002/ece3.424

Van Strien MJ, Keller D, Holderegger R (2012) A new analytical approach to landscape genetic modelling: least-cost transect analysis and linear mixed models. Mol Ecol 21 (16):4010-4023. doi:10.1111/j.1365-294X.2012.05687.x

Von der Lippe M, Kowarik I (2007) Long-distance dispersal of plants by vehicles as a driver of plant invasions. Conserv Biol 21 (4):986-996. doi:10.1111/j.1523-1739.2007.00722.x

Wagner A, Schabetsberger R, Sztatecsny M, Kaiser R (2011) Skeletochronology of phalanges underestimates the true age of long-lived Alpine newts (Ichthyosaura alpestris). Herpetological Journal 21 (2):145-148 
754 Woltz HW, Gibbs JP, Ducey PK (2008) Road crossing structures for amphibians and reptiles: Informing design through behavioral analysis. Biol Cons 141 (11):2745-2750. doi:10.1016/j.biocon.2008.08.010

756

757 
758 Table 1. Correlative analyses on pairwise data. Simple and partial Mantel correlations (r) between

759 pairwise genetic distance matrices $(G)$ and various effective distance matrices among males and females

760 located at less than $S=12 \mathrm{~km}$ from the A6 highway $\left(M_{A 6}\right.$ and $\left.F_{A 6}\right)$ or from the LGV-PSE high-speed

761 railway $\left(M_{L G V-P S E}\right.$ and $\left.F_{L G V-P S E}\right)$. Effective distance matrices were based on the null model of isolation-by-

762 distance $(I B D)$, on the model of isolation-by-barrier $(I B B)$, and on three models of isolation-by-resistance

763 according to the putative effects of slope $\left(I B R_{\text {slope }}\right)$, land cover $\left(I B R_{L C}\right)$ or both $\left(I B R_{\text {slopeLC }}\right)$. Significant

764 Mantel correlations at $\alpha=0.05$ are in bold.

\begin{tabular}{|c|c|c|c|c|c|}
\hline Dataset & $n^{\mathrm{a}}$ & Investigated pattern & Mantel test ${ }^{b}$ & Mantel correlation $r$ & P-value \\
\hline \multirow{8}{*}{$M_{A 6}$} & \multirow{8}{*}{153} & $I B D$ & $G \sim I B D$ & 0.0893 & $\mathbf{0}$ \\
\hline & & \multirow{3}{*}{$I B R$} & $G \sim I B R_{\text {slope }} / I B D$ & -0.0066 & 0.5854 \\
\hline & & & $G \sim I B R_{L C} / I B D$ & 0.0534 & 0.0569 \\
\hline & & & $G \sim I B R_{\text {slope } L C} / I B D$ & 0.0089 & 0.3896 \\
\hline & & \multirow{4}{*}{$I B B$} & $G \sim I B B / I B D$ & -0.0388 & 0.962 \\
\hline & & & $G \sim I B B / I B R_{\text {slope }}$ & -0.0421 & 0.981 \\
\hline & & & $G \sim I B B / I B R_{L C}$ & -0.0379 & 0.965 \\
\hline & & & $G \sim I B B / I B R_{\text {slope } L C}$ & -0.041 & 0.977 \\
\hline \multirow{8}{*}{$F_{A 6}$} & \multirow{8}{*}{154} & $I B D$ & $G \sim I B D$ & 0.0725 & $\mathbf{0}$ \\
\hline & & \multirow{3}{*}{$I B R$} & $G \sim I B R_{\text {slope }} / I B D$ & -0.0178 & 0.7213 \\
\hline & & & $G \sim I B R_{L C} / I B D$ & 0.0069 & 0.4146 \\
\hline & & & $G \sim I B R_{\text {slope } L C} / I B D$ & -0.0099 & 0.6024 \\
\hline & & \multirow{4}{*}{$I B B$} & $G \sim I B B / I B D$ & -0.0285 & 0.9351 \\
\hline & & & $G \sim I B B / I B R_{\text {slope }}$ & -0.0304 & 0.959 \\
\hline & & & $G \sim I B B / I B R_{L C}$ & -0.0277 & 0.9291 \\
\hline & & & $G \sim I B B / I B R_{\text {slopeLC }}$ & -0.0298 & 0.957 \\
\hline \multirow{8}{*}{$M_{L G V-P S E}$} & \multirow{8}{*}{160} & $I B D$ & $G \sim I B D$ & 0.0441 & 0.009 \\
\hline & & \multirow{3}{*}{$I B R$} & $G \sim I B R_{\text {slope }} / I B D$ & -0.0037 & 0.5335 \\
\hline & & & $G \sim I B R_{L C} / I B D$ & -0.0051 & 0.5794 \\
\hline & & & $G \sim I B R_{\text {slope } L C} / I B D$ & -0.0076 & 0.5804 \\
\hline & & \multirow{4}{*}{$I B B$} & $G \sim I B B / I B D$ & 0.0119 & 0.2697 \\
\hline & & & $G \sim I B B / I B R_{\text {slope }}$ & 0.0128 & 0.2258 \\
\hline & & & $G \sim I B B / I B R_{L C}$ & 0.0116 & 0.2727 \\
\hline & & & $G \sim I B B / I B R_{\text {slopeLC }}$ & 0.0126 & 0.2418 \\
\hline \multirow{8}{*}{$F_{L G V-P S E}$} & \multirow{8}{*}{162} & $I B D$ & $G \sim I B D$ & 0.0572 & 0.003 \\
\hline & & \multirow{3}{*}{$I B R$} & $G \sim I B R_{\text {slope }} / I B D$ & -0.012 & 0.6533 \\
\hline & & & $G \sim I B R_{L C} / I B D$ & 0.0068 & 0.4046 \\
\hline & & & $G \sim I B R_{\text {slope } L C} / I B D$ & 0.0046 & 0.4565 \\
\hline & & \multirow{4}{*}{$I B B$} & $G \sim I B B / I B D$ & 0.0188 & 0.1528 \\
\hline & & & $G \sim I B B / I B R_{\text {slope }}$ & 0.02 & 0.1369 \\
\hline & & & $G \sim I B B / I B R_{L C}$ & 0.0185 & 0.1648 \\
\hline & & & $G \sim I B B / I B R_{\text {slope } L C}$ & 0.0198 & 0.1189 \\
\hline
\end{tabular}


${ }^{a}$ Number $n$ of genotypes in dataset.

$767 \quad{ }^{\mathrm{b}} \mathrm{G} \sim \mathrm{A}$ corresponds to a simple Mantel test between the genetic distance matrix $\mathrm{G}$ and the matrix $\mathrm{A} ; \mathrm{G} \sim$

768 A/B corresponds to a partial Mantel test between the genetic distance matrix $\mathrm{G}$ and the matrix A

769 partialling out the matrix B. Mantel tests were performed with 1000 restricted permutations. 
Fig. 1 Characteristics of the study area and sampling scheme in Bourgogne (France). The A6 divided

772

773

774

775

776

777

778

779

780

781

782

783

784

785

786

787

788

789

790

791

792

793

794

795

796

797

798

799 highway and the LGV-PSE highspeed railway are in thick and dotted thick lines respectively. (a) Localisation of the 225 ponds were alpine newts were sampled, of the 225 additional fictive sites used in CDPOP simulations and of main habitat features in the study area. The intersection of the two infrastructures delimits four distinct sectors (A, B, C and D). (b) Relief and main landscape entities in the study area. Western and eastern geologic depressions in L'Auxois are respectively numbered 1 and 2.

Fig. 2 Mantel correlograms showing the relationships between inter-individual genetic distances and Euclidean distance classes (defined every $3000 \mathrm{~m}$ ) in (a) males, (b) females and (c) one of the ten simulated datasets at generation 100. $r$ : standard Mantel correlation with 1000 permutations. Error bars bound the $95 \%$ confidence interval about $r$ as determined by bootstrap resampling. Upper and lower confidence limits (dotted line) bound the $95 \%$ confidence interval about the null hypothesis of no spatial structure as determined by permutation.

$*: p$-value $<0.05 ; * *: p$-value $<0.01 ; * * *: p$-value $<0.001$.

Fig. 3 Spatial genetic structures inferred from TESS. (a) Estimates of the true number $K$ of clusters using the DIC criterion averaged over each five runs (mean \pm SD). (b) Estimated membership ( $y$-axis) of each individual ( $x$-axis) in clusters 1 and 2 . The $40 \%$ threshold (dotted line) approximately delimits individuals from cluster 1 (Terre-Plaine) according to figure 3c. (c) Spatial distribution of clusters 1 and 2 in the study area. Black dots stand for the sampling points. Contour lines stand for the interpolated membership of individuals in cluster 1 , using a kriging function.

Fig. 4 Analyses of alpine newt data using sPCA. Large white and black squares stand for highly negative and positive scores respectively. Small squares stand for low sPCA scores. White arrows and corresponding roman numerals indicate various inferred boundaries (see text for details). (a) Map of the first global sPCA scores in dataset $M$; analyses led to highly similar patterns in dataset $F$ (data not shown). (b) Map of the second global sPCA scores in dataset $M$; (c) Map of the second global sPCA scores in dataset $F$. (d) Map of the third global sPCA scores in dataset $F$; white dashes delimit an area in which females located in the direct vicinity of the highway show high genetic similarity. (e) Screeplots of 
800 sPCA eigenvalues in datasets $M$ and $F$; retained structures are filled in black; letters in italics refer to

801 maps a to d.

802

803 Fig. 5 Detection of the A6 highway (circles) and the LGV-PSE high-speed railway (diamonds) simulated

804 as total barriers to gene flow, using partial Mantel tests with 1000 restricted permutations in 100

805 simulated datasets (see text for details). Analyses were performed from the placement of each

806 infrastructure to the generation 200. The placement of the fictive highway and railway occurred

807 respectively at generations 100 (standing for the year 1969) and 112 (standing for year 1981), while the

808 real empirical sampling occurred at generation 141 (year 2010). Black arrows indicate for each

809 infrastructure the elapsed time until first significant barrier detection $(\alpha=0.05)$. $r$ : partial Mantel

810 correlation values. Black symbols: significant partial Mantel tests at $\alpha=0.05$. Gray symbols: significant

811 partial Mantel tests at $\alpha=0.1$. Error bars bound the $95 \%$ confidence interval about $r$ as determined by

812 bootstrap resampling.

813

814 